\title{
Water and energy-based optimisation of a "MiniCity": A system dynamics approach
}

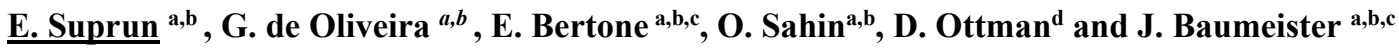 \\ ${ }^{a}$ Systems Modelling Group - Cities Research Institute - Griffith University - Gold Coast Campus \\ ${ }^{b}$ School of Engineering and Built Environment - Griffith University - Gold Coast Campus \\ ${ }^{c}$ SeaCities - Cities Research Institute - Griffith University - Gold Coast Campus \\ ${ }^{d}$ Faculty Of Society And Design, Abedian School Of Architecture, Bond University, Gold Coast \\ Email: e.suprun@griffith.edu.au
}

\begin{abstract}
Urban sprawls in Australia and several countries around the world have introduced a number of social, economic, and environmental issues for residents and urban planners, highlighting the need for new urban development concepts.

In recent years, the concept of a vertical sprawl called "MiniCity" has been presented. The objective of a successful "MiniCity", compared to traditional high-rises, is to be as self-sufficient and self-contained as possible; whilst also minimising issues such as car dependency, loss of agricultural land and natural habitats, water and air pollution, and poorer health and wellbeing, which are common for residents in low-density, lowrise areas and developments. To date however, the viability of a MiniCity has yet to be properly addressed.

Arguably, the predominant needs for a community are water, energy and food. In this research study, a System Dynamics model was developed to simulate supply and demand of the water and energy systems, as well as their interaction, for a hypothetical MiniCity located in South-East Queensland, Australia. The models were conceptualised based on expert knowledge, with data and equations collected from local Gold Coast sources and from the literature. Preliminary results show the complex, but expected, dynamics and interactions between the two systems, and their dependence to critical input parameters, such as climate data, roof area, number of floors, to name a few. Future work will focus on adding other critical modelling components such as food production and thus analyse the water-energy-food nexus.

The final, validated model will allow the optimisation of critical MiniCity parameters and the identification of suitable locations that can maximise the socio-economic and environmental viability of the MiniCity.
\end{abstract}

Keywords: MiniCity, systems modelling, urban planning, water-energy nexus 


\section{INTRODUCTION}

Cities are often labelled as the most complex creations of humankind (Baumeister and Ottman, 2014). Different expertise and professionals (e.g. engineers, architects, urban planners) are needed to design and manage specific elements and challenges of a city. The question thereby is how to start to describe an entire city as one system with fewer complexities.

The dream of an own house on the own piece of land normally creates horizontally spread developments. The consequences are partly visible as extensive street areas, which are accompanied by an immense network of invisible infrastructure for water, wastewater, and energy. The economic, social and environmental challenges of such "urban sprawl" approach are becoming increasingly evident, especially in Australian cities such as Melbourne and Sydney.

Inspired by a sketch published more than 100 years ago demonstrating a condensed interpretation of a city, the concept of "MiniCity" was introduced (Baumeister and Ottman, 2014). It is a hybrid, which is vertical and urban, and at the same time, it is a stacked up mini-piece of suburbia for 300 residents. Light and materials choice determined the preliminary sizing of such development to around $50 \mathrm{~m} \times 50 \mathrm{~m} \times 50 \mathrm{~m}$. The goal of a MiniCity would be to be as self-sufficient as possible thus minimizing the issues and challenges of the traditional urban sprawls.

Why has a MiniCity never been built? Is there a reason, or is it just a matter of omission? Designers normally would praise the charms of this hybrid, and its difference would be already often a success by itself. However, to gather the support of all the potential decision-makers, a qualitative-only design would often not be sufficient, especially when disruptive new concepts are introduced. With this study, we developed an effective collaboration between architects/designers and modellers, in order to quantify the feasibility of the MiniCity concept by simulating and optimising all the complex systems and interactions occurring in any built environment. A System Dynamics (SD) approach was deemed appropriate for this research task, due to the ability of this modelling approach to account for complex interactions, as well as feedback loops and time delays (Sterman, 2000). This paper presents the methodology and preliminary findings specifically related to the water and energy systems of a MiniCity, with input data for the models collected for the Gold Coast, Australia.

\section{MATERIALS AND METHODS}

\subsection{System Dynamics - Water component}

$\mathrm{SD}$ is a modelling approach providing conceptual tools to understand the structure and dynamics of complex systems; it also enables users to simulate such complex systems (Sterman, 2000). In a MiniCity, managing water supply infrastructure and providing alternative water sources would be critical for its success. Changes in water consumption and water supply are the result of structural relationships that lead to changes over time. Those changes are dynamic in nature, and in this research, a SD model that captures the relationships is developed (Figure 1).

The model has been designed to assess the effects of changes in the water distribution system on the availability of water to develop estimates of the water surpluses and/or deficits in MiniCity. As a consequence, it would be possible to optimise the design (e.g. roof area, affecting rainwater collection; or number of floors, affecting the number of occupants and in turn water demand).

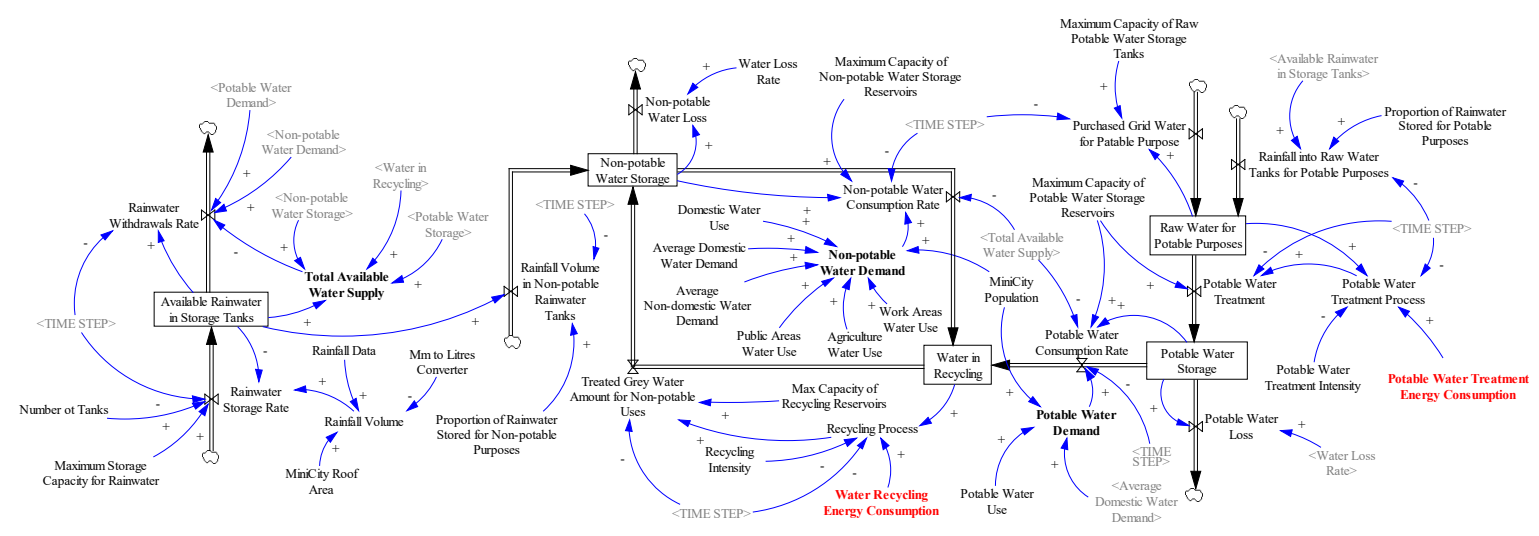

Figure 1. MiniCity SD model - Water component. In red, energy-related variables 
The use of SD to address challenges associated with urban water supply is increasing within the international water sector (Sahin et al., 2018; Bertone et al., 2016; Park et al., 2014; Rehan et al., 2014). The generic water demand-supply system developed by Chung et al. (2008) has been tailored based on the MiniCity's need. This system simulates water flows to meet water demands. The model simulated a 5-year period, equating to a time horizon of 2005-2010. The selected time period is long enough to account not only for seasonal weather variations, but also for longer-term climate cycles such as El Niño, whilst still maintaining a relatively short simulation time. The model was simulated using the time unit of days. The Euler method was selected for numerical integration purposes. The model was constructed and simulated using Vensim DSS system dynamics software, version 7.3 (Vensim 2019). Where relevant numerical data were not available, technical reports were consulted in order to provide data for the model parameters and initial states (Beal and Stewart, 2011; BOM, 2019). Overall, the variables in SD are categorised into stock variables, flow rate variables, constants, and auxiliary variables. The stock variables (e.g. Potable water storage) represent the cumulative quantities, the flow rate variables (e.g. Potable water consumption rate) represent the rate of change of cumulative quantities, and the constants (e.g. MiniCity Population) do not change over time in a time interval. The auxiliary variables (e.g. Potable water treatment process) are used to express the non-linear relationship between some variables in the model. The causal and logical relationships amongst the variables are abstracted into mathematical relations (i.e. state and auxiliary equations) to conduct quantitative analysis.

Model sub-systems include water demand, water supply, as well as treatment and recycling components. Water requirements are linked to consumption per person per day estimates for the Gold Coast region (Beal and Stewart, 2011). The water demand sub-system estimates the total water demand of a MiniCity. The model components describe the amounts of water needed for potable and non-potable purposes related to household, public-use, and agricultural water demands. Potable water is consumed by MiniCity dwellings for drinking purposes, showering, bathing and washing dishes. Non-potable water components include domestic use (e.g. toilets and cloth washing), public use (e.g. public kitchen/toilets, public areas such as playgrounds and community parks), work areas use and agricultural use. The mathematical representation of potable water demand $(P W D)$ is:

$$
P W D=D W D_{\text {aver }} \times P W \times M C P
$$

where $D W D_{\text {aver }}$ is the average domestic water demand; $P W$ is potable water use; and $M C P$ is MiniCity population.

Overall, according to Beal and Stewart (2011), the average household water consumption for the 2000-2010 period is approximately 150 litres per person per day $(1 / \mathrm{p} / \mathrm{d})$ in South East Queensland. This comprises: showering and bathing 30.5\%; drinking water, food preparation and tap water 19\%; clothes washing 21\%; toilet flushing 16.5; dishwashing 2\%; irrigation 5\%; and other 5\%. Multiple components of the same type or none of a specific type can be incorporated into a model for a specific region.

The water storage was modelled using two stocks: potable water storage and non-potable water storage. The water supply sub-system structure illustrates that water accumulates through three types of water sources, namely rainfall, reclaimed greywater from wastewater treatment plants, and grid water. The rainwater and recycled water are the most essential components within the non-potable water supply system, as the primary goal of the MiniCity bulk water system is to have sufficient water supply to meet the demand in any particular day. Grid water is an external water source transported from outside in case there is not enough harvested rainwater to cover water demands for potable purposes. The model makes allowances for $10 \%$ of water loss due to failures and leakages in the MiniCity distribution system. The non-potable water storage $(N P W)$ stock is influenced by rainfall volume $(R N P)$, treated grey water $(T G W)$, non-potable water consumption rate $(N P W C)$, and water loss $(N P W L)$ represented as:

$$
N P W(t)=N P W(0)+\int[R N P+T G W-N P W C-N P W L] d t
$$

The recycling process shows the potable and non-potable water being recycled, so that after treatment, water becomes available again. Approximately $90 \%$ of water is recycled for non-potable usage (Baumeister and Ottman, 2014), which in turn leads to a lower MiniCity freshwater demand. To reflect this, treated greywater amount for non-potable uses is represented as a decision rule influenced by the maximum capacity of recycling reservoirs $\left(R R C_{\max }\right)$, and the recycling process $R P$ :

$$
T G W=\min \left(R R C_{\max }, R P\right)
$$

The model structure reflects the real-world problem that the amount of potable water available is subject to the amount of raw water available and the treatment capacity. Raw water availability increases with grid water purchases and rainfall into raw water reservoirs. 
The rainwater storage rate $(R W R)$ is determined by the amount of rainfall available for rainwater harvesting $(R W)$, maximum rain storage capacity $\left(R S C_{\max }\right)$, number of tanks $(N T)$, and the rainfall volume in storage $\operatorname{tanks}(R F)$ :

$$
\left.R W R=\min \left(\left(R S C_{\max } \times N T\right)-R W\right), R F\right)
$$

Historical rainfall data from Gold Coast, Queensland was obtained from the Bureau of Meteorology (BOM, 2019) to simulate the rainfall collection capacity of the MiniCity.

\subsection{System Dynamics - Energy component}

Figure 2 shows the stock-and-flow diagram for the energy supply-demand using the SD modelling approach. Ataei et al. (2015) evaluated the techno-economic viability of off-grid hybrid energy systems with solar and wind penetration in office buildings. Their results showed that integration of photovoltaic panels and wind turbines with storage batteries is economically feasible and technically reliable in off-grid applications. Thus, these were included in the model. Decentralised energy storage is logically designed to tackle the intermittent nature of the wind and solar sources according to the energy produced and required demand. The total capacity of decentralised energy storage is calculated based on the storage capacity of each battery and its respective amount. The distributed energy production comes from the power outputs (Eqns. $5 \& 6$ ) for solar $\left(P_{s p}\right)$ and wind $\left(P_{w t}\right)$ generation (Dagdougui et al., 2012).

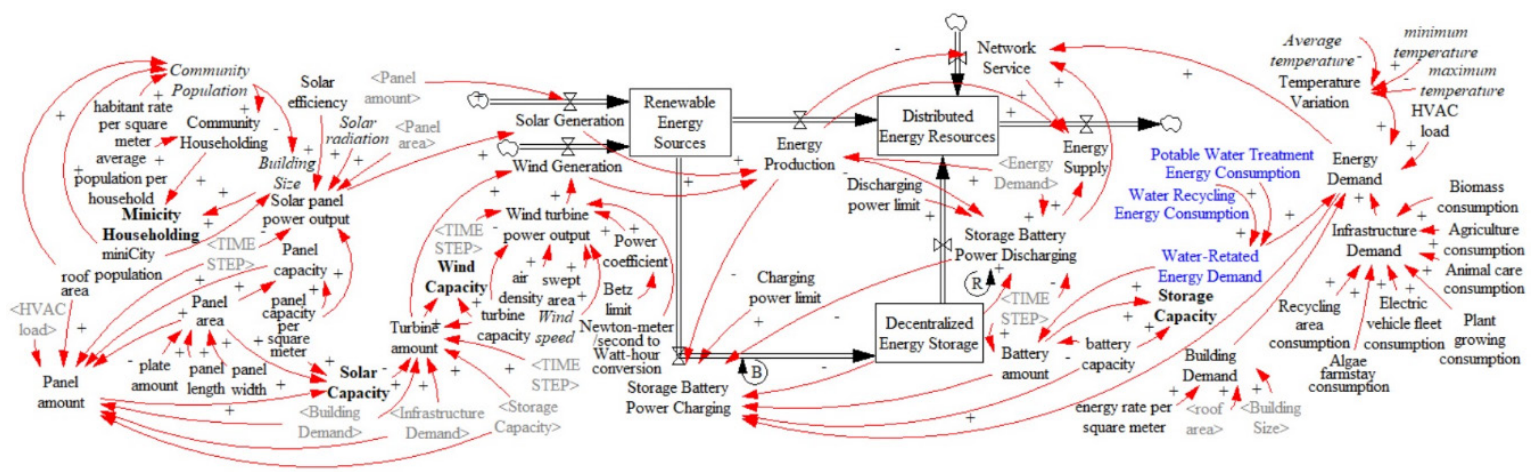

Figure 2. MiniCity SD model - Energy distribution component. In blue, water-related variables

$$
\begin{aligned}
& P_{s p}(t)=n_{s p} p_{s p} A_{s p} R_{s}(t) \\
& P_{w t}(t)=n_{w t} c_{w t}(1 / 2) \rho_{a i r} A_{w t} v_{w}(t)^{3}
\end{aligned}
$$

The number of panels $\left(n_{s p}\right)$ is determined according to the solar capacity per square meter of each panel, whose maximum amount is subjected to the ratio of the roof area of the building by the panel area $\left(A_{s p}\right)$, and its efficiency $\left(p_{s p}\right)$ in converting the solar radiation $\left(R_{s}\right)$. The wind capacity is subjected to the wind regime of the region. The turbine capacity is set accordingly to its potential output based on the theoretical maximum (Betz limit) power coefficient $\left(c_{w t}\right)$, air density $\left(\rho_{\text {air }}\right)$, swept area $\left(A_{w t}\right)$ in the wind turbine, and daily average wind speed $\left(v_{w}\right)$, which determines the number of turbines $\left(n_{w t}\right)$ for wind generation. This hybrid energy system is grid-connected to the network service $\left(P_{n e t}\right)$ to ensure the system reliability when the energy supplied from the distributed generation and decentralized storage are not enough to meet the required demand.

The state variables: distributed energy production $\left(E_{\text {dep }}\right)$; decentralized energy storage $\left(E_{\text {des }}\right)$; and energy supply $\left(E_{\text {sup }}\right)$, are dependent on the time-varying auxiliary variables, energy delivery $\left(P_{\text {del }}\right)$ and apportionment $\left(P_{a p p}\right)$, power charging $\left(P_{c h}\right)$ and discharging $\left(P_{d i s}\right)$, according to the following equations:

$$
\begin{aligned}
& E_{\text {dep }}(t)=E_{\text {sup }}^{t_{0}}+\int_{t_{0}}^{T}\left[P_{w g}(t)+P_{s g}(t)-P_{c h}(t)-P_{d e l}(t)\right] d t \\
& E_{\text {des }}(t)=E_{\text {sup }}^{t_{0}}+\int_{t_{0}}^{T}\left[P_{c h}(t)-P_{d i s}(t)\right] d t \\
& E_{\text {sup }}(t)=E_{\text {sup }}^{t_{0}}+\int_{t_{0}}^{T}\left[P_{\text {del }}(t)+P_{\text {dis }}(t)+P_{\text {net }}(t)-P_{\text {app }}(t)\right] d t
\end{aligned}
$$




\subsection{System Dynamics - Water and Energy Integration}

Given the intent of the MiniCity being a semi-autonomous system, water and energy should be managed in an integrated manner. Understanding and quantifying the water-energy nexus, i.e. the interactions between the water and energy systems, is key to obtaining reliable simulation outputs. A single framework is required to assess the interactions between energy and water in its nexus implementation (Dai et al., 2018). Hamilton et al. (2019) reported the virtual storage of energy related commodities like potable water as a cost-effective approach to maximize the utilization of renewable resources. The water and energy SD models were linked together to investigate the impact of management options for one resource on the other. To connect the two models, the interaction points between water and energy distribution systems were identified in the models. The identification of energy consumption for water related use ends is a starting point towards the energy water nexus. The developed model establishes this primary interaction by specifying the energy use for water treatment and recycling in the energy demand as shown in Figure 3.

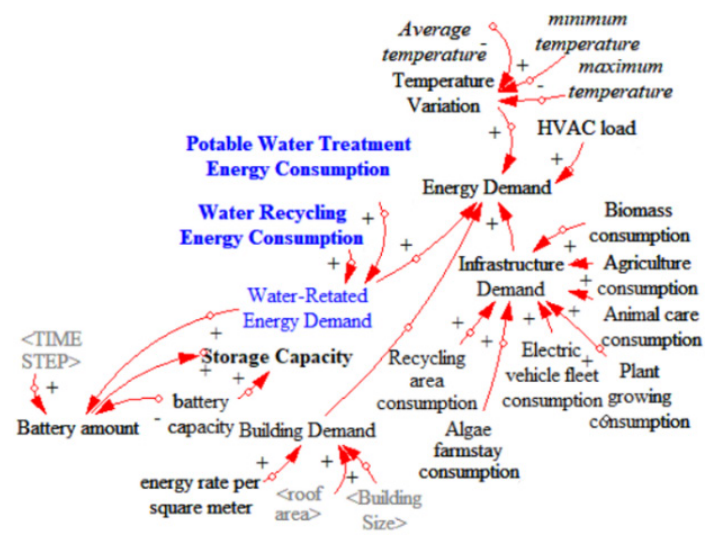

Figure 3. MiniCity CLD for Energy Demand. In blue, water-related variables

The MiniCity water supply incorporates three types of alternative water sources (i.e. rainwater, recycled greywater from wastewater treatment plants, and additionally purchased grid water). Producing potable water is reliant on the treatment processes so that raw water is safe to drink. Increase in potable water demand leads to the increase in energy demand (i.e. energy consumption for water treatment and delivery). The water model (Figure 1) incorporated the Potable water treatment energy consumption (PWEC) variable (highlighted in red) to link two models. Potable water treatment process $(P W T P)$ is represented as a decision rule influenced by the capacity of the water treatment works, and the available raw water $(R W)$ :

$$
P W T P=I F T H E N E L S E\left(R W<\left(\frac{P W E C}{P W T I}\right), R W,\left(\frac{P W E C}{P W T I}\right)\right)
$$

where PWTI is potable water treatment intensity $(\mathrm{KWh} / \mathrm{L})$, which was estimated through a combination of historical treatment plant data and outputs collected from the literature.

Similarly, the water model is connected to the energy model through the water recycling process, where energy is required to reclaim greywater. The wastewater treatment and delivery process are characterised by the Recycling process $(R P)$ variable, which depends on the recycling intensity $(R I)$ and water recycling energy consumption $(W R E C)$ :

$$
R P=I F T H E N E L S E\left(W R<\left(\frac{W R E C}{R I}\right), W R,\left(\frac{W R E C}{R I}\right)\right)
$$

where $W R$ is water in recycling [L].

As can be seen, the water supply system is interdependent with the energy demand system at a utility level. Impacts of the management options associated with one resource on the other allow for optimal resources consumption and reduction of environmental impacts. Critical input parameters, such as roof size (affecting both rainwater collection and solar photovoltaic energy production) can be optimised by taking into account both water and energy requirements.

\section{RESULTS}

The preliminary results of water and energy distribution within the MiniCity are summarised in this section by using the simulation outputs from the SD model. Once the SD model was developed, the dimensional 
consistency of the model was verified in order to test its structural validity. Then a number of validation tests were conducted to check whether the model behaved realistically under extreme conditions. For instance, an extreme condition might occur if the MinyCity population increased significantly. For such scenario, the capacity of recycling facilities is not sufficient, so more grid water needs to be purchased. Results showed that the model behaved realistically under extreme conditions.

As mentioned above, the water supply structure incorporates three alternative water sources, namely rainfall, recycled wastewater, and grid water. The rainwater and recycled water are the most critical components of the non-potable water distribution system. Given the region under investigation, harvested rainwater is often insufficient to meet the water demand on any particular day (Beal and Stewart, 2011). After the "dry" days, the water shortage appears followed by the need to adjust water storage on a daily basis in order to balance demand-supply trends. It goes without saying that a decrease in water levels cannot be avoided as the water usage has to be maintained at the same level, unless water demand reduction strategies are implemented. A wastewater collection and treatment system have a positive influence on maintaining the volume of water used for non-potable purposes. In order to compensate potable water shortage, additional grid water is purchased. However, effective wastewater collection and treatment system allows reducing the municipal water consumption by proportionally distributing rainwater between potable and non-potable storage reservoirs. Nevertheless, the supply of treated greywater is limited by reclaimed water capacity, which is determined by the amount of wastewater, and recycling infrastructure, such as pipelines and amount of energy produced. When the water demand is lower than the capacity, the recycled water supply equals to the demand. Figure 4 demonstrates the simulation outputs in regard to potable and non-potable water storages. The parameters change over time, and a trend following the rainfall pattern can be clearly observed. In the case of water shortage, the treated wastewater will produce water for non-potable purposes and will, in turn, reduce the water shortage in potable water supply following the rainwater distribution change.

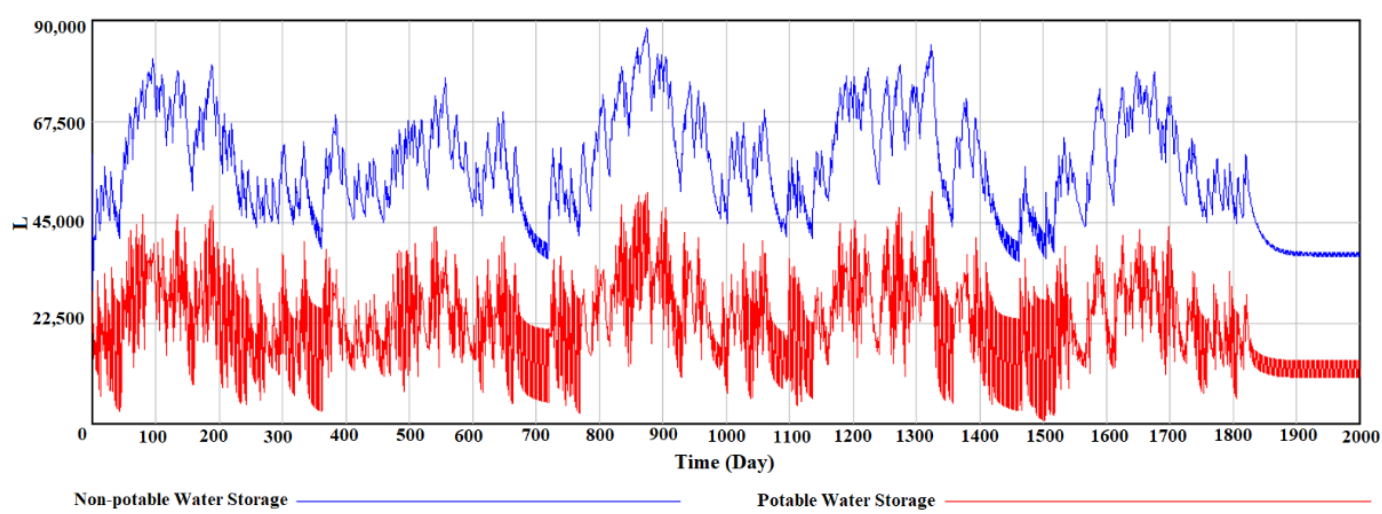

Figure 4. Simulation outputs - potable and non-potable water storages

Figure 5 presents the simulation outputs of the energy distribution. The graph shows the convergence of the network service with the energy deficit between supply and demand during the entire time horizon, which ensures the system reliability that validates the dynamic behaviour of the developed model to meet the required demand.

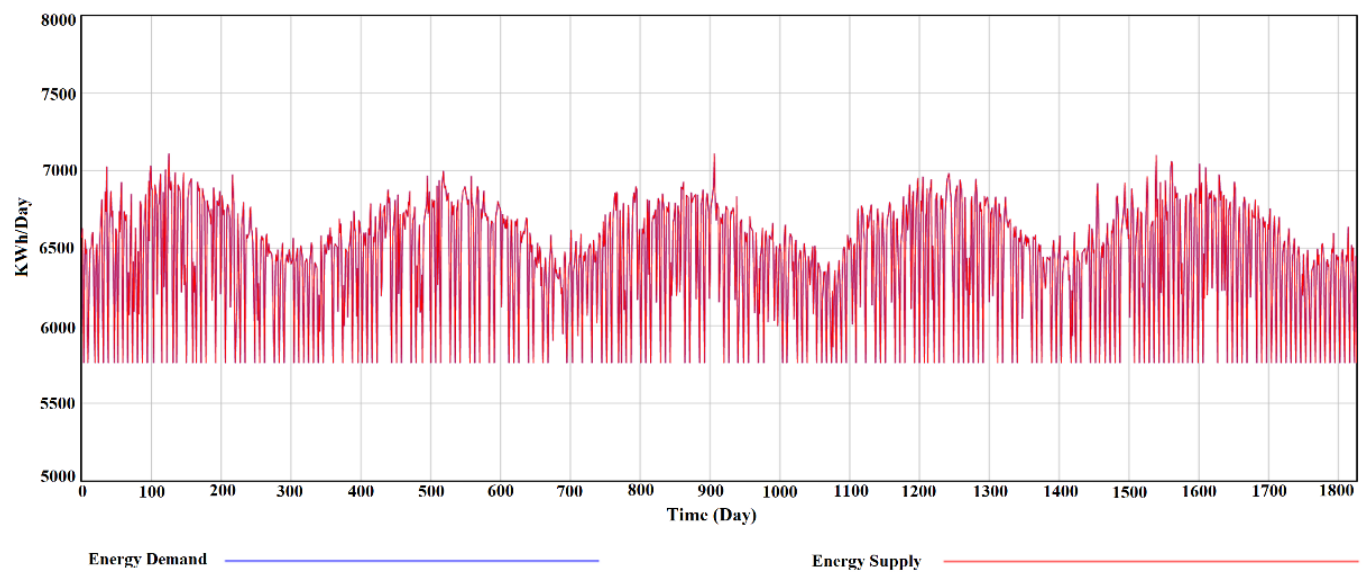

Figure 5. Simulation outputs - supply-demand energy deficit and network service 


\section{DISCUSSION AND CONCLUSION}

A System Dynamic model was developed to simulate the water and energy systems of a vertical urban sprawl concept called "MiniCity". Initially, two separate (water and energy) models were developed, relying on expert opinion and climate data for the Gold Coast region (Australia). The two models were then merged to account for the water-energy nexus. Results showed strong, expected interdependencies between the water and energy system, with "self-sufficiency" to be achieved through an integrated optimisation of MiniCity features (e.g. number of floors or roof height), appliances (e.g. water efficient fixtures) and location (affecting e.g. solar radiation and rainfall)

The system sizing of energy capacity will be further investigated accordingly to the water distribution. Following validation, future work will focus on adding other components (e.g. food) to the model, and optimising the critical input parameters (e.g. roof size, floors number, location) in order to maximize the economic, environmental and social viability of the "MiniCity" urban development concept. If proven to be effective, such an urban design solution could contribute to alleviating pressing socio-economic issues related to urban sprawls around Australia and the world.

\section{ACKNOWLEDGMENTS}

This research work was partially funded by Cities Research Institute, Griffith University.

\section{REFERENCES}

Ataei, A., Nedaei, M., Rashidi, R. and Yoo, C. (2015). Optimum design of an off-grid hybrid renewable energy system for an office building. Journal of Renewable and Sustainable Energy, 7(5), 053123.

Baumeister, J. and Ottman, D. (2014). Urban Ecolution: A pocket generator to explore future solutions for healthy and ecologically integrated cities. UWA Publishing.

Beal, C.D. and Stewart, R.A. (2011). South East Queensland Residential End Use Study: Final Report. Urban Water Security Research Alliance, Technical Report No.: 47.

Bertone, E., Sahin, O., Richards, R. and Roiko, A. (2016). Extreme events, water quality and health: A participatory Bayesian risk assessment tool for managers of reservoirs. Journal of Cleaner Production, 135, 657-667.

BOM (2019). Bureau of Meteorology. Australia Government; [accessed 2019 June 1]. https://www.bom.gov.au.

Chung, G, Kim, J.H. and Kim. T-W. (2008). System dynamics modeling approach to water supply system. KSCE Journal of Civil Engineering. 12(4), 275.

Dai, J., Wu, S., Han, G., Weinberg, J., Xie, X., Wu, X., Song, X., Jia, B., Xue, W. and Yang, Q. (2018). Waterenergy nexus: A review of methods and tools for macro-assessment. Applied Energy, 210, 393 - 408.

Dagdougui, H., Minciardi, R., Ouammi, A., Robba, M. and Sacile, R. (2012). Modeling and optimization of a hybrid system for the energy supply of a green building. Energy Conversion and Management, 64, $351-363$.

Hamilton, J., Negnevitsky, M., Wang, X. and Lyden, S. (2019) High penetration renewable generation within Australian isolated and remote power systems, Energy, 168, 684-692.

Park, S., Jeon, D-H. and Jung, S-Y. (2014). Developing efficient management strategies for a water supply system using system dynamics modelling. Civil Engineering and Environmental Systems, 31(3), 189208.

Rehan, R., Knight, M.A., Unger, A.J.A. and Haas, C.T. (2014). Financially sustainable management strategies for urban wastewater collection infrastructure - development of a system dynamics model. Tunnelling and Underground Space Technology, 39, 116-129.

Sahin, O., Bertone, E., Beal, C. and Stewart, R.A., (2018). Evaluating a novel tiered scarcity adjusted water budget and pricing structure using a holistic systems modelling approach. Journal of Environmental Management, 215, 79-90.

Sterman, J.D. (2000). Business dynamics: systems thinking and modeling for a complex world. The McGrawHill Companies; Printed in the United States of America.

Vensim (2019). Vensim ${ }^{\circledR}$ Software. Version 7.3. Ventana Systems; [accessed 2019 June 1]. https://vensim.com. 